\title{
Surface Active Properties and LCST Behavior of Oligo(propylene oxide-block- ethylene oxide) Allyl Ether Siloxane Surfactants in Aqueous Solution
}

\author{
Doo Won Kim, ${ }^{`}$ Chul Hwan Lim, Jae Kon Choi, ${ }^{\dagger}$ and Si Tae Noh ${ }^{\ddagger}$ \\ Shin. Jin Chem. Ind. Co. Ltd. R\&D Center, Ansan $425-100$. Korea \\ - Department of Polvmer Science \& Engineering. Chosun Cniversity $501-759$. Korea \\ -Department of Chemical Engineering. Hamang Lniversin, Ansan $+25-791$. Korea \\ Received December 6, 2003
}

\begin{abstract}
Polydisperse oligo(PO- $b$-EO) allyl ether siloxane surfactants were synthesized by the hydrosilylation reaction of OMTS with Allyl-oligo(PO- $b$-EO) series. The surface tension of siloxane surfactants increased with increasing the $\mathrm{EO}$ chain length while it decreased with increasing the $\mathrm{PO}$ ratio. However. the sedimentation time of the aqueous solution showed opposite trend to the surface tension data. Both the surface tension and sedimentation time of the aqueous solution containing inorganic electrolyte gradually decreased as the content of inorganic electrolyte increased because of the surface arrangement of surfactant molecules. However. they increased with an increase of $\mathrm{pH}$ values due to the hydrolysis of the siloxane backbone. The $\mathrm{C}_{\mathrm{p}}$ values tended to increase with the increase in the EO chain length and decrease of the PO ratio. It seems that intermolecular interaction between $\mathrm{PO} / \mathrm{EO}$ block copolymer and water affects the variation of transition temperature.
\end{abstract}

Key Words : Polydisperse oligo(PO- $b$-EO) allyl ether siloxane surfactants, Surface tension, Surface arrangement, Hydrolysis. $\mathrm{C}_{\mathrm{p}}$ values

\section{Introduction}

Silicone surfactants are a class of novel surfactants consisting of a permethylated siloxane backbone with one or more hydrophilic groups attached. Most siloxane surfactants are intermediate molecular weight copolymers. This class of surfactants is highly surface active in both aqueous and nonaqueous media. lowering surface tension to nearly $20-25$ dyne/cn. ${ }^{1}$

Silicone surfactants are classified into nonionic or ionic type silicone surfactants. Nonionic type silicone surfactants have low critical micelle concentration (CMC), a cloud point of micelle solution at specific temperature. and foam property compared with ionic type silicone surfactants. Especially. cloud point at specific temperature is a particular characteristic of nonionic type silicone surfactants and ionic surfactants. ${ }^{21.22}$

Nonionic type surfactants have an advantage that allows the ratio and molecular weight of the $\mathrm{PO} / \mathrm{EO}$ block oligomer to be varied. These nonionic type silicone surfactants consist of a siloxane backbone and ethylene oxide (EO) oligomer as hydrophilic functional groups. However, when hydrophilic functional groups within nonionic type silicone surfactants were a linear type and the end capping of the hydrophilic functional groups was a hydroxy type, hydrolytic stability decreased. surface tension increased, and chemical attack on the silicone surfactants backbone easily occurred in aqueous solution. Therefore, novel nonionic type silicone surfactants were prepared either by the grafting of a siloxane backbone with EO oligomer containing the methoxy groups as the tip

\footnotetext{
${ }^{*}$ To whom all correspondence should be addressed. e-mail: sjkdwo hammail.net
}

structure or by block copolymerization of EO as the hydrophilic part and propylene oxide (PO) as the hydrophobic part. The advantages of these structural types are good hydrolytic stability. low surface tension, increased emulsion power. wetting power. and foam stability. Also. chemical attack on the latter structural type occurred in aqueous solution less than on the former structural type.

The advantage of grafted copolymers is that they are more resistant to hydrolysis and chemical attack than linear polymers. The major class is a polydimethylsiloxane to which polyethers have been grafted through a hydrosilylation reaction. This process results in an alkyl-pendant copolymer. in which the poly(alkyl oxide) groups are attached to the siloxane backbone through a series of hydrolytically stable -Si-C- bonds. The other class is a polydimethylsiloxane to which polyethers have been attached through a condensation reaction. This creates an alkosy-end blocked copolymer, in which the poly(alkylene oxide) groups are attached at the ends of the siloxane backbone through - $\mathrm{Si}-\mathrm{O}-\mathrm{C}$ bonds. This linkage offers limited resistance to hydrolysis under a neutral or slightly basic condition, but breaks down in strong acidic and basic condition.

The solubility of siloxane surfactants in water is related to the hydration of the ether oxygen of the poly (oxyethylene) groups. An increase in temperature leads to a decrease in the number of hydrogen bonds, which raises the micellar weight and decreases the $\mathrm{CMC}$. If the temperature continues to increase, the micelles become so large and the number of intermicellar interactions increases to such a great extent that a sudden onset of turbidity is perceptible even to the naked eye. This temperature. so called cloud point, is one of the major characteristics of nonionic type surfactants. A further rise in temperature causes the solution to begin to separate 
into two phases: one is surfactants-rich. and the other is surfactants-depleted with no or few micelles present. The aqueous phase behavior of these siloxane surfactants tends to be quite different from that of the poly(oxyethylene)based materials. The less hydrophilic siloxane surfactants are simply water insoluble. whereas the more hydrophilic siloxane surfactants are miscible with water in all proportions below their cloud temperature. Furthermore, salts decrease the cloud point due to the salting-out effect and raise the cloud point because of the salting-in effect. ${ }^{1,2}$

In the present study, polydisperse oligo(propy lene oxideblock-etlyylene oxide) allyl ether siloxane surfactants [OAoligo(PO- $b$-EO) series] were synthesized by the hydrosilylation reaction of octamethyltetrasiloxane (OMTS) with oligo(propylene oxide-block-ethylene oxide) allyl ether. [Allyl-oligo(PO-b-EO) series]. ${ }^{1+}$ We measured the surface tension. sedimentation time of aqueous solutions, and the phase transition temperature (cloud point : $\mathrm{C}_{\mathrm{p}}$ ). Furthermore. surface active properties according to the variation in the $\mathrm{pH}$ values and inorganic electrolytes content in aqueous solutions were researched.

\section{Experimental Section}

Materials. $3 \mathrm{H}$. $5 \mathrm{H}-$ Octamethyltetrasiloxane (OMTS, F.W. $=282.64 \mathrm{~g} / \mathrm{mol}$, Lancaster Synthesis Ltd., UK) was used without further purification. Specifications for other materials and Allyl-oligo(PO- $b-\mathrm{EO})$ series are provided in reference No. 3, 17 and 18. Also, detailed measuring methods are explained in reference No. 17 and 18 .

Synthesis of OA-oligo(PO-b-EO) series. The hydrosilylation reaction for synthesizing OA-oligo(PO- $b$-EO) series is described in reference No. 17, where the siloxane backbone was applied as OMTS. Table I shows HLB (Hydrophilic Lipophilic Balance) values, molecular weight. phase transition temperature (cloud point: $C_{p}$ ), and synthetic recipe of the OA-oligo(PO- $b$-EO) series.

\section{Results and Discussion}

Characterization of OA-oligo(PO- $b$-EO) series. OA-
oligo(PO-b-EO) series is easily synthesized by the hydrosily lation reaction of OMTS with active hydrogen and Allyloligo(PO- $b$-EO) series with an allyl group, using a platinum catalyst. According to Chalk and Harrods mechanism, a binuclear complex is formed by the reaction between oxidative platinum catalyst and an organic compound with an unsaturated double bond. The Pt(IV) intemediate $(\pi$ bond complex) reacts with the siloxane. which has an active hydrogen via the $\mathrm{Pt}(\mathrm{II})$ intermediate ( $\sigma$-bond complex). And then the formed binuclear complex reacts with another compound, completing the hydrosilylation reaction. . $^{11.13-16}$

Characterization related to the hydrosilylation reaction of the $\mathrm{OA}$-oligo(PO- $b$ - $\mathrm{EO})$ series was fully demonstrated in reference No. 3. 17 and 19.

Surface tension. According to the previous reports, the surface tension of an aqueous solution containing siloxane wetting agent is less than that of conventional surfactants because the silicone holds the hydrophobic segment. Also. it has been suggested that the hydrophobic segment could be formed at a lower concentration or critical concentration due to these hydrophobic groups. ${ }^{4-8}$

Figure 1 shows aqueous solutions of the OA-oligo(PO- $b$ EO) series as a function of the surface tension against concentration. As shown in Figure 1, the surface tension decreased with increasing concentration in an aqueous solution. Also, the surface tension decreased dramatically to about $0.01 \mathrm{wt} \%$ and then stayed above $0.01 \mathrm{wt} \%$ with little changes. Therefore. the critical micelle concentration (CMC) could be estimated at around $0.01 \mathrm{wt} \%$ from these results.

Figure 1-(a) shows the surface tension of the $\mathrm{OA}$ oligo(EO) series. The surface tension of the $O A$-oligo(EO) series tended to increase according to the increase in the EO chain length and quickly decrease to CMC with increasing concentration in aqueous solution. However, the surface tension of the $\mathrm{OA}$-oligo(EO) series above $\mathrm{CMC}$ was similar in spite of the increase in the EO chain length. It seems that the surface tension was affected by the decrease of the OMTS ratio according to the increase in the EO chain length. Figure 1-(b) shows the surface tension of the OAoligo(PO- $b$-EO) series. which is a $\mathrm{PO} / \mathrm{EO}$ block oligomer with a chain length of 7 molecules. In Figure 1-(b). the

Table 1. HLB, molecular weight, phase transition temperature (Cloud point) according to the LCST behavior and synthetic recipe of the OAoligo(PO-b-EO) allyl ether siloxane surfactants

\begin{tabular}{|c|c|c|c|c|c|c|c|c|}
\hline \multirow{2}{*}{ Notation } & \multicolumn{2}{|c|}{ Ally l-oligo( $\mathrm{PO}-b$-EO) series } & \multirow{2}{*}{$\begin{array}{l}\text { OMTS } \\
\text { (mole) }\end{array}$} & \multirow{2}{*}{$\begin{array}{l}\mathrm{CPA}^{\prime \prime} \\
(\mathrm{ppm})\end{array}$} & \multirow{2}{*}{ 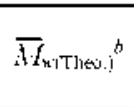 } & \multirow{2}{*}{$\bar{M}_{n \mid \operatorname{Exp},{ }^{c}}$} & \multirow{2}{*}{$\mathrm{HLB}^{d}$} & \multirow{2}{*}{$\begin{array}{c}\text { Cloukd point } \\
\left({ }^{\circ} \mathrm{C}\right)\end{array}$} \\
\hline & Type & Mole & & & & & & \\
\hline $\mathrm{OA}-\mathrm{EO} 4$ & $\mathrm{~A}-\mathrm{EO} 4$ & 2 & 1 & 70 & 751.22 & 755.20 & 9.37 & 32.2 \\
\hline OA-EO5 & A-EO5 & 2 & 1 & 70 & 839.32 & 840.14 & 10.48 & 35.0 \\
\hline OA-EO6 & A-EO6 & 2 & 1 & 70 & 927.44 & 926.92 & 11.39 & 41.5 \\
\hline $\mathrm{OA}-\mathrm{EO} 7$ & $\mathrm{~A}-\mathrm{EO} 7$ & 2 & 1 & 70 & 1015.54 & 1014.37 & 12.13 & 50.9 \\
\hline OA-POIEO6 & A-PO1EO6 & 2 & 1 & 70 & 1043.40 & 1044.52 & 10.12 & 37.5 \\
\hline $\mathrm{OA}-\mathrm{PO} 2 \mathrm{EO} 5$ & $\mathrm{~A}-\mathrm{PO} 2 \mathrm{EO} 5$ & 2 & 1 & 70 & 1071.64 & 1072.59 & 8.21 & 31.0 \\
\hline OA-PO3EO4 & A-PO3EO4 & 2 & 1 & 70 & 1099.70 & 1100.02 & 6.40 & 28.0 \\
\hline
\end{tabular}

${ }^{a}$ : Hydrogen hexachloroplatinate (IV) hydrate. ${ }^{b}$. Theoretical number average molecular weight. $"$ : Experimental arerage molecular weight calculated by hydroxy value. ": Hydrophilic Lipophilic Balance calculated by Grittin equation (HLB=E 5, where $\mathrm{E}$ is a molecular weight ratio ( ${ }^{\circ}, 0$ ) of ethy lene oxide).

: Phase transition temperature (cloud point: $\mathrm{C}_{p}$ ) estimated by mid-point 

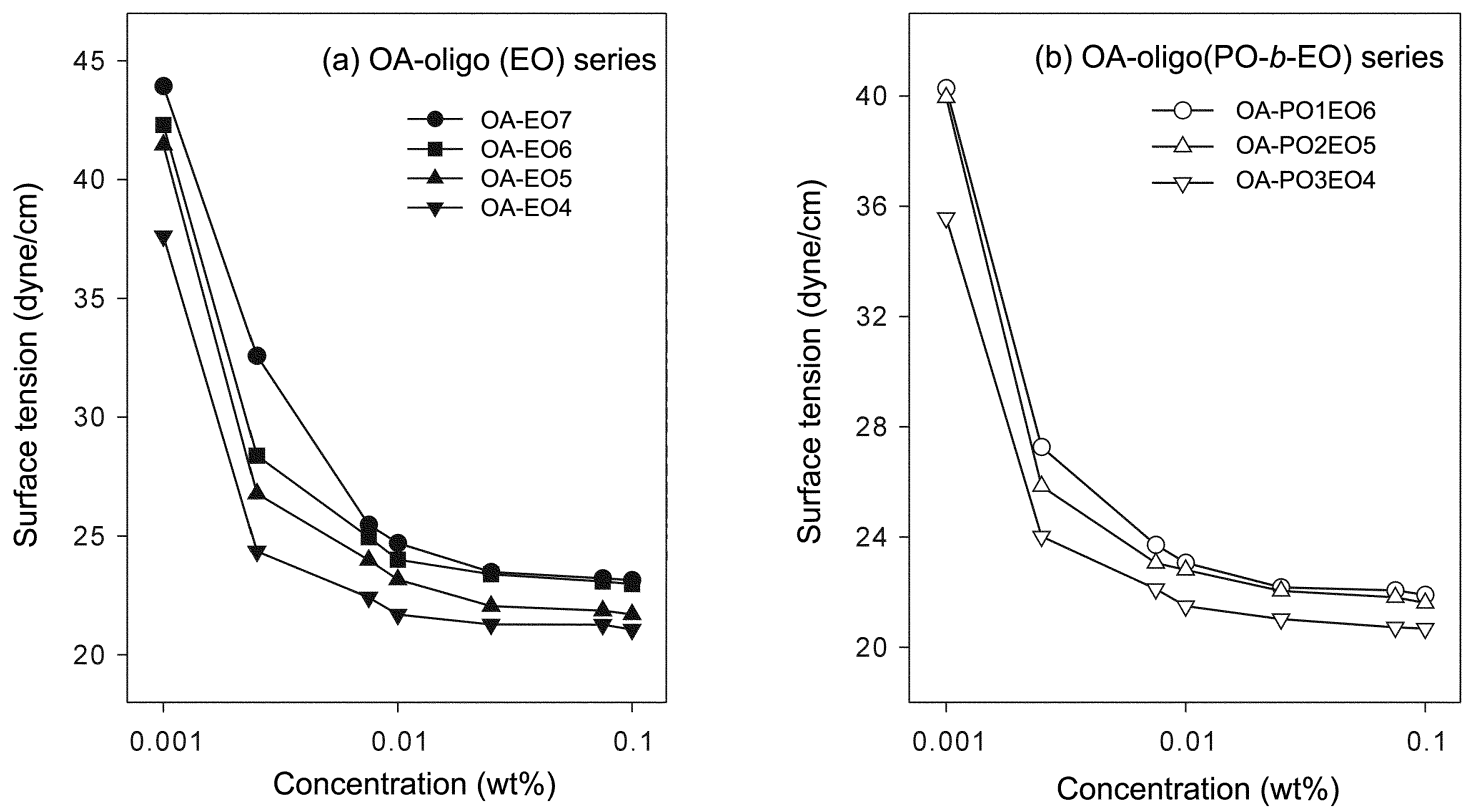

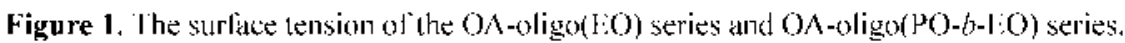

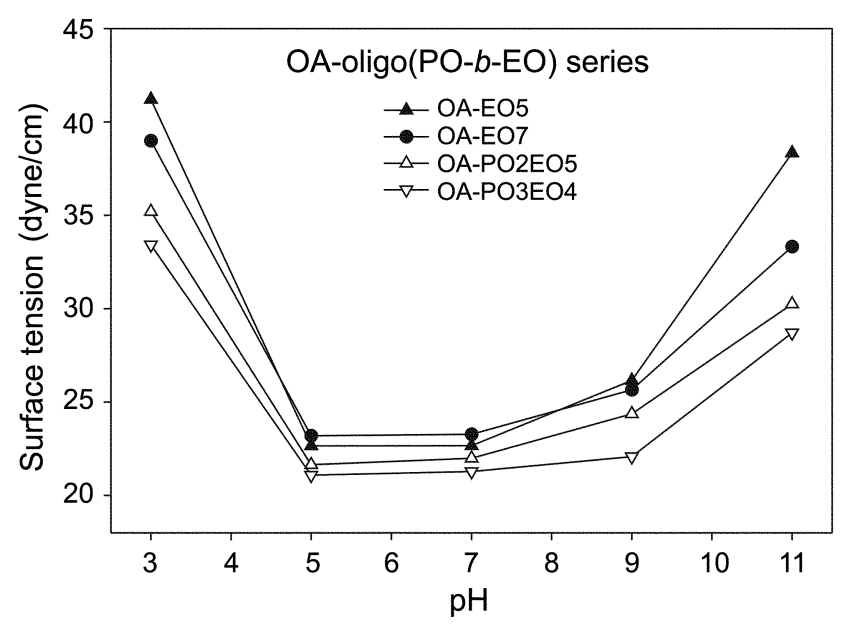

Figure 2. The surface tension of the $O A$-oligo(EO) series and $O A-$ oligo( $\mathrm{PO}-h-\mathrm{EO})$ series according to the variation in $\mathrm{pH}$ values. (Concentration of acueous solution: $0.1 \mathrm{w} \%$ ).

surface tension of an aqueous solution was decreased quickly to the $\mathrm{CMC}$ according to the increase in the $\mathrm{PO}$ chain length and stayed above CMC without change. Also, when we compared figure $1-(a)$ with $1-(b)$, the surface tension of the $\mathrm{OA}$-oligo( $\mathrm{PO}-b$-EO) series shows lower values than the OAoligo(EO) series. Consequently, it seems that increases in the hydrophobic ratio due to increasing the $\mathrm{PO}$ unit resulted in a decrease in the surface tension of the OA-oligo $(\mathrm{PO}-b-\mathrm{EO})$ series.

Figure 2 and 3 show the change in the surface tension with variations in the $\mathrm{pH}$ values and the standing time for $\mathrm{pH} 3$ and $\mathrm{pH} 11$, respectively. In Figure 2 , the surface tension shows $U$-type curves according to the increase in $\mathrm{pH}$ values. The surface tension of siloxane surfactants was increased for $\mathrm{pH} 3$ and $\mathrm{pH} \mathrm{11}$, such as for a strong acid and alkali. But the surface tension for neutral $\mathrm{pH}$ values, such as $\mathrm{pH} 5$ and $\mathrm{pH} 7$. was observed to be lower than $\mathrm{pH} 3$ and $\mathrm{pH} 11$. For most siloxane surfactants hydrolysis in acjueous solution occurs easily. Hydrolysis is especially fast in acid and alkali aqueous solutions. ${ }^{2}$ Therefore, the OA-oligo(PO- $b$-ГOO) series in an aqueous solution of strong acid and alkali was easily hydrolyzed, and the surface tension of the acpueous solution increased at $\mathrm{pH} 3$ and $\mathrm{pH} 11, \ln$ Figure 3 , the surface tension of siloxane surfactants was observed according to the variation in standing time, where $\mathrm{pH}$ values were fixed at 3 and 11. The surface tension of OA-ГOS and OA-ГO7 increased dramatically at $12-36 \mathrm{~h}$, remaining constantly after $36 \mathrm{~h}$. However, the surface tension of OA-PO2FO5 and $\mathrm{OA}-$ $\mathrm{PO} 35 \mathrm{SO} 4$ gradually increased during $36 \mathrm{~h}$ and also remaining constantly after $36 \mathrm{~h}$. Also, the surface tension of the $\mathrm{EO}$ series was higher than the $\mathrm{PO} / \mathrm{\Gamma} \mathrm{O}$ block series. It seems that the hydrolytic stability of the siloxane backbone increased as the length of the $E O$ chain increased. And, the slope of the OA-oligo(PO- $b$-EO) series was less than the OA-oligo(EO) series when comparing the hydrolysis rate of the $\mathrm{OA}$ oligo( $\mathrm{EO}$ ) series with that of the OA-oligo( $(\mathrm{O}-b$-EO) series. It seems that siloxane surfactants with the $\mathrm{PO}$ block oligomer is more stable for hydrolysis than the $\mathrm{EO}$ group. ${ }^{2}$

Figure 4 shows the surface tension of the OA-oligo( $\mathrm{PO}-b$ EO) series with the content of an inorganic electrolyte, such as calcium chloride. As shown in Figure 4, the surface tension tended to decrease with increasing concentration of aqueous solutions. Also, the surface tension of aqueous solutions tended to decrease according to the increase in the inorganic electrolyte content. It seems these molecules were constantly rearranged after surfactant molecules were moved to the surface of the aqueous solutions. That is to say, because salts, such as phosphate, citrate, sulfate, and chloride lead to a "salting out" rather than "salting in" of a nonionic surfactant, the solubility of the surfactant in the aqueous solutions decreased, and molecules of a nonionic 

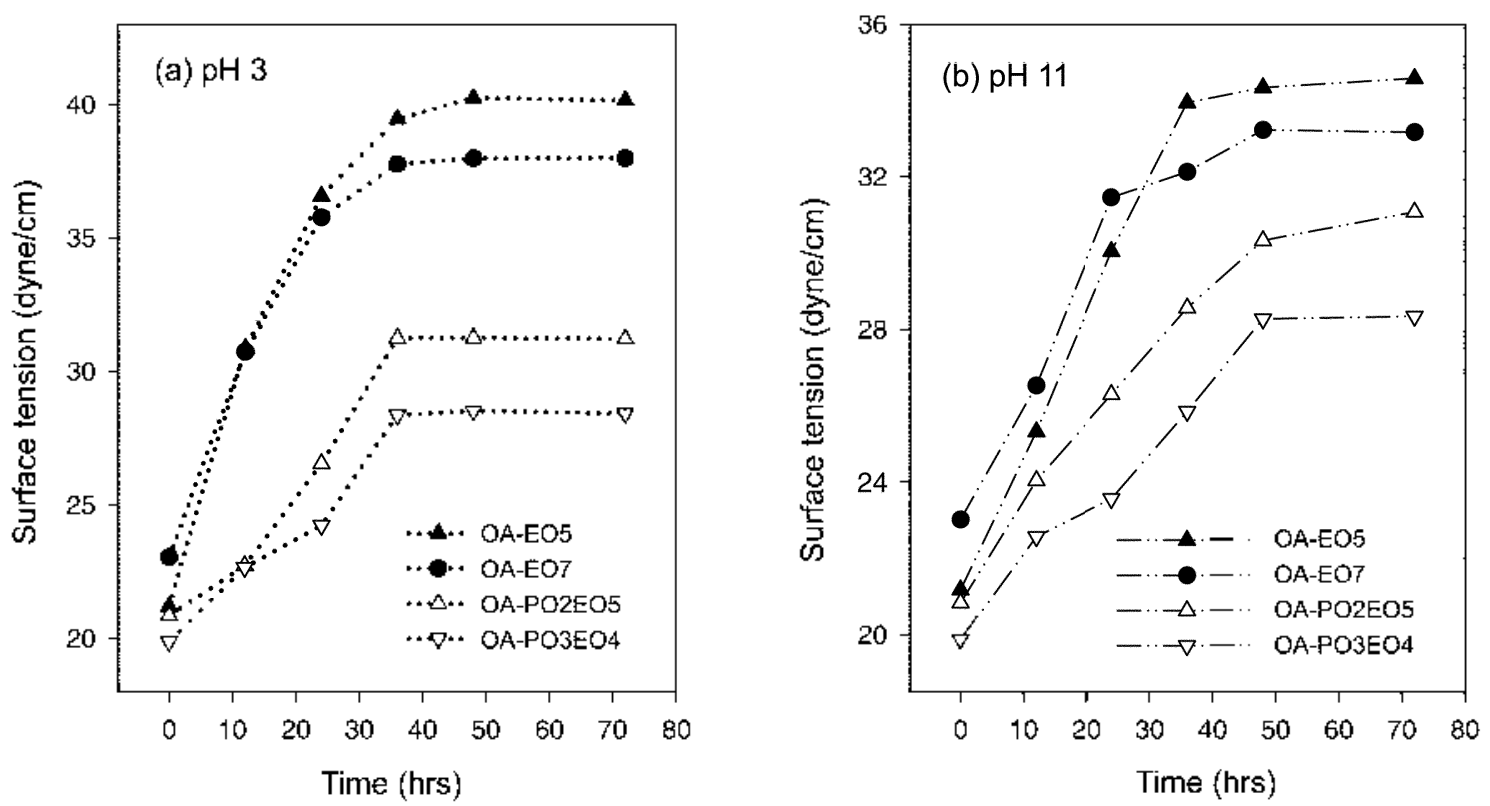

Figure 3. The surface tension of the $O A$-oligo(EO) series and $O A$-oligo(PO- $h$-EO) series according to the variation of standing time at $\mathrm{pH} 3$ and 11. (Concentration of aqueous solution: $0.1 \mathrm{w} \%$ ).
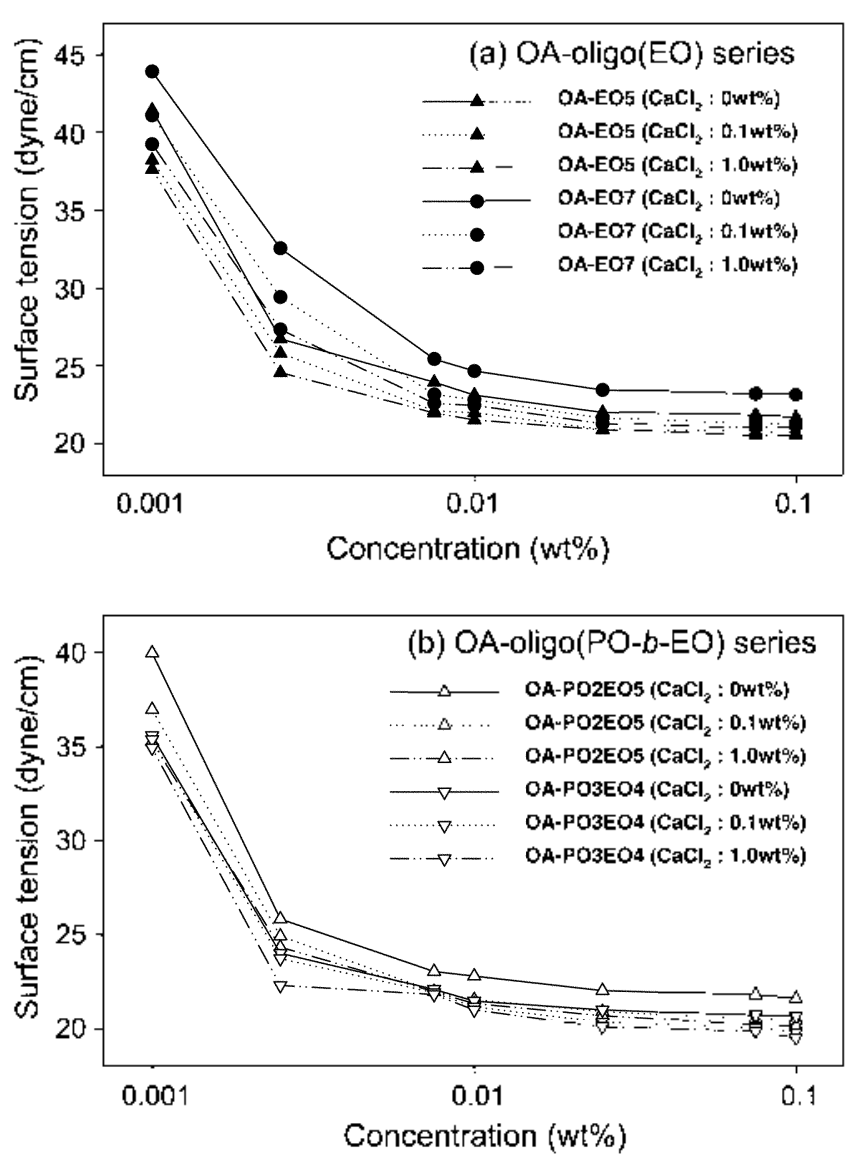

Figure 4. The surface tension of the $\mathrm{OA}$-oligo $(\mathrm{EO})$ series and $\mathrm{OA}$ oligo(PO- $h$-EO) series according to the content of an inorganic electrolyte.

surfactant were arranged toward the surface of the aqueous solutions. Consequently, it seems that the surface tension of the aqueous solutions decreased because the number of molecules per unit area at the interface of the solutions increased. ". in

Table 2 shows CMC values of the OA-oigo(PO- $b$-FO) series with various $\mathrm{CO}$ chain length and $\mathrm{PO}$ ratios. CMC values increased according to the increase in the $C O$ chain length and to the decrease in the $\mathrm{PO}$ ratio. This was due to the association of micelles at the lower concentration with the increased hydrophobic ratio. When an inorganic electrolyte was added to the aqueous solutions, $\mathrm{CMC}$ values increased according to the increase in the $\mathrm{OO}$ chain length and to the decrease in the PO ratio too. However, CMC values of the aqueous solutions having inorganic electrolyte were higher than those of the blank, and the surface tension calculated at $\mathrm{CMC}$ was observed to be lower than that of the blank.

LCST behavior for the chain length and structure of hydrophilic moicties. Nonionic silicone surfactants with hydrophilic and hydrophobic groups, such as $\mathrm{EO}$ and $\mathrm{PO}$ within the surfactant structure, can exhibit lower critical solution temperature (LCST) behavior according to the variation in the $\mathrm{EO}$ chain length and ratio of the $\mathrm{PO} / \mathrm{EO}$ block copolymer. An aqueous solution of these nonionic wetting agents exists as clear phase due to the hydrogen bonds with water below the phase transition temperature (cloud point: $C_{p}$ ). However, because the hydrophobichydrophobic intermolecular interactions between surfactants are stronger than the hydrogen bonds, an aqueous solution appears as a turbid phase separated between surfactants and water at critical temperature or phase transition temperature. ${ }^{5.6}$

Figure 5 shows $C_{p}$ values of the $O A$-oligo $(\mathrm{EO})$ series and the $\mathrm{OA}$-oligo( $\mathrm{P}^{3} \mathrm{O}-b$-EO) series using $\mathrm{TOA}$, or a thermal optical analyzer, an instrument that measures the phase 
Table 2. Critical micelle concentration (CMC) of the $O A$-oligo(LO) series and $O A$-oligo(PO- $b$-LO) series according to the variation of the $\mathrm{PO}$ /EO block copolymer

\begin{tabular}{|c|c|c|c|c|c|c|}
\hline \multirow{2}{*}{ Notation } & \multirow{2}{*}{$\begin{array}{l}\mathrm{CMC}^{\mathrm{w}} \\
\text { (w/\%) }\end{array}$} & \multirow{2}{*}{$\begin{array}{c}k \mathrm{mc}^{b} \\
\text { (dyne/cm) }\end{array}$} & \multicolumn{2}{|c|}{$\mathrm{CaCl}_{2}\left(0.1 \mathrm{w} t^{[2 \%} \%\right)$} & \multicolumn{2}{|c|}{$\mathrm{CaCl}_{2}(1,0 \mathrm{w} \%)$} \\
\hline & & & C.MC $(1+t \%)$ & $\gamma_{\text {CAC }}(\mathrm{dynt} / \mathrm{cm})$ & CMC $(w+\%)$ & Kuc (dyncism) \\
\hline OA-EO4 & 0.00868 & 22.1569 & 0.00974 & 21.6883 & 0.01077 & 20.9078 \\
\hline OA-EOS & 0.00905 & 23.3115 & 0.01035 & 21.7861 & 0.01133 & 21.1726 \\
\hline OA-EOG & 0.01050 & 23.5099 & 0.01153 & 22.0347 & 0.01329 & 21.3624 \\
\hline $\mathrm{OA}-\mathrm{EO} 7$ & 0.01268 & 23.6526 & 0.01374 & 22.0637 & 0.01446 & 21.5310 \\
\hline OA-PO1EO6 & 0.00963 & 23.2000 & 0.01028 & 21.8147 & 0.01120 & 21.1816 \\
\hline OA-PO2EO5 & 0.00838 & 22.9718 & 0.00904 & 21.6357 & 0.01007 & 21.0182 \\
\hline $\mathrm{OA}-\mathrm{PO} 3 \mathrm{EO} 4$ & 0.00786 & 21.7996 & 0.00818 & 21.3577 & 0.00961 & 21.0053 \\
\hline
\end{tabular}

": Critical micelle concentration (C.MC) determined by extrapolation. "s. Surface tension calculated at $C \mathrm{MC}$
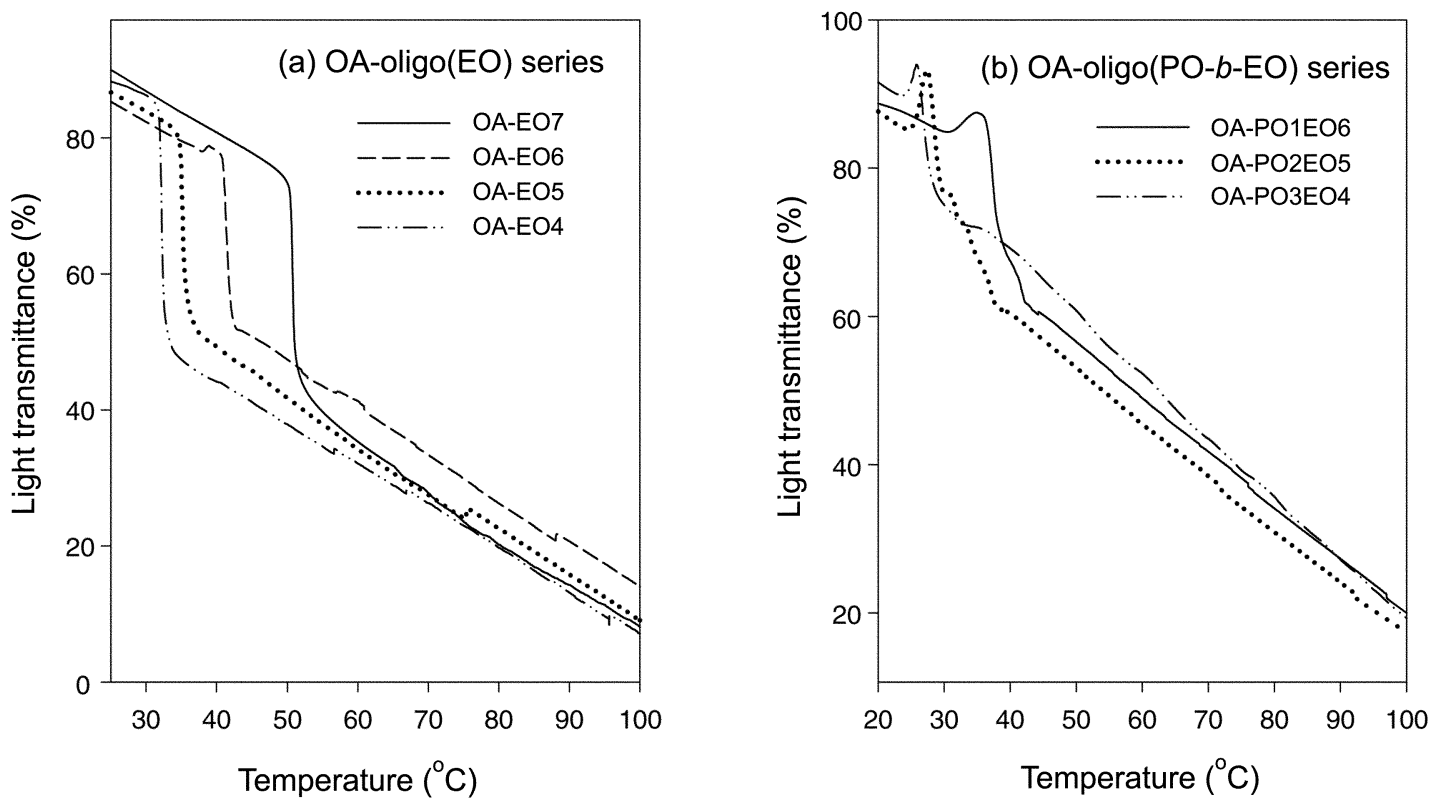

Figure 5. I'he phase transition temperalure (clotd point) thermograms of the $\mathrm{OA}$-oligo(t:O) series and OA-oligo(PO- $b$ - $1: 0)$ series by $1 \mathrm{OA}$. (Concentration of aqueous solution: $5.0 \mathrm{wt} \%$ ).

transition temperature of an aqueous solution. It comprises a hot chamber, a central processor, and an optical polarized microscope. ${ }^{20}$ In Figure 5 -(a), the $C_{p}$ values of the OAoligo(EO) series tend to increase with increasing $\mathrm{EO}$ chain length. It seems that the hydrogen bonds between $\mathrm{EO}$ groups and water, according to the increase in the $\mathrm{EO}$ chain length, where more numerous than for the interaction of the OMIS with hydrophobic groups. Figure 5-(b) shows IOA thermograms of the $\mathrm{OA}$-oligo( $(\mathrm{PO}-b$ - $\mathrm{EO})$ series according to the variation of the $\mathrm{P} O \mathrm{O} / \mathrm{EO}$ ratio. $\mathrm{C}_{p}$ values tend to decrease with the number of $\mathrm{PO}$ unit having hydrophobic groups. $\mathrm{EO}$ groups with hydrophilicity decreased as $\mathrm{PO}$ groups with hydrophobicity increased. Therefore, the hydrophobic interactions of $\mathrm{PO}$ groups were more numerous than the hydrophilic interactions of $E O$ groups, and $C_{p}$ values of the OAoligo( $\mathrm{PO}-b$ - $\mathrm{EO}$ ) series were observed at a lower temperature according to the increase in the $\mathrm{PO}$ unit. Consequently, it seems that $C_{p}$ values of the OA-oligo( $\mathrm{EO}$ ) series and OAoligo( $\mathrm{PO}-b$-EO) series were influenced by intermolecular interactions between $\mathrm{PO} / \mathrm{EO}$ block oligomer and water.
Table 1 shows $C_{p}$ values of the OA-oligo(EO) series and the $\mathrm{OA}$-oligo( $\mathrm{PO}-b$ - $\mathrm{EO}$ ) series according to the variation in the $\mathrm{PO} / \mathrm{EO}$ block copolymer.

Sedimentation time of aqueous solutions. Figure 6 represents a wetting power as a function of the sedimentation time for the $\mathrm{EO}$ chain length and the variation in the $\mathrm{PO}$ / $\mathrm{EO}$ ratio. Because the wetting agent dissolved in an aqueous solution was placed between cotton with hydrophobicity and water with hydrophilicity, the wetting power of the $\mathrm{OA}$ oligo( $\mathrm{l}^{2} \mathrm{O}-b$-EO) series on an aqueous solution surface can be determined by the sedimentation time of the cotton.

Most aqueous solutions were well absorbed into the cotton, and sedimentation time tended to decrease with increasing concentration in an aqueous solution. Figure 6-(a) shows the sedimentation time of the OA-oligo( $(\mathrm{CO})$ series for the EO chain length. The sedimentation time quickly decreased with increasing concentration in an aqueous solution to $1.0 \mathrm{wt} \%$, but remained uniformly above $1.0 \mathrm{wt} \%$. Also, the sedimentation time decreased with increasing the chain length of the EO. Figure 6-(b) shows the sedimentation 

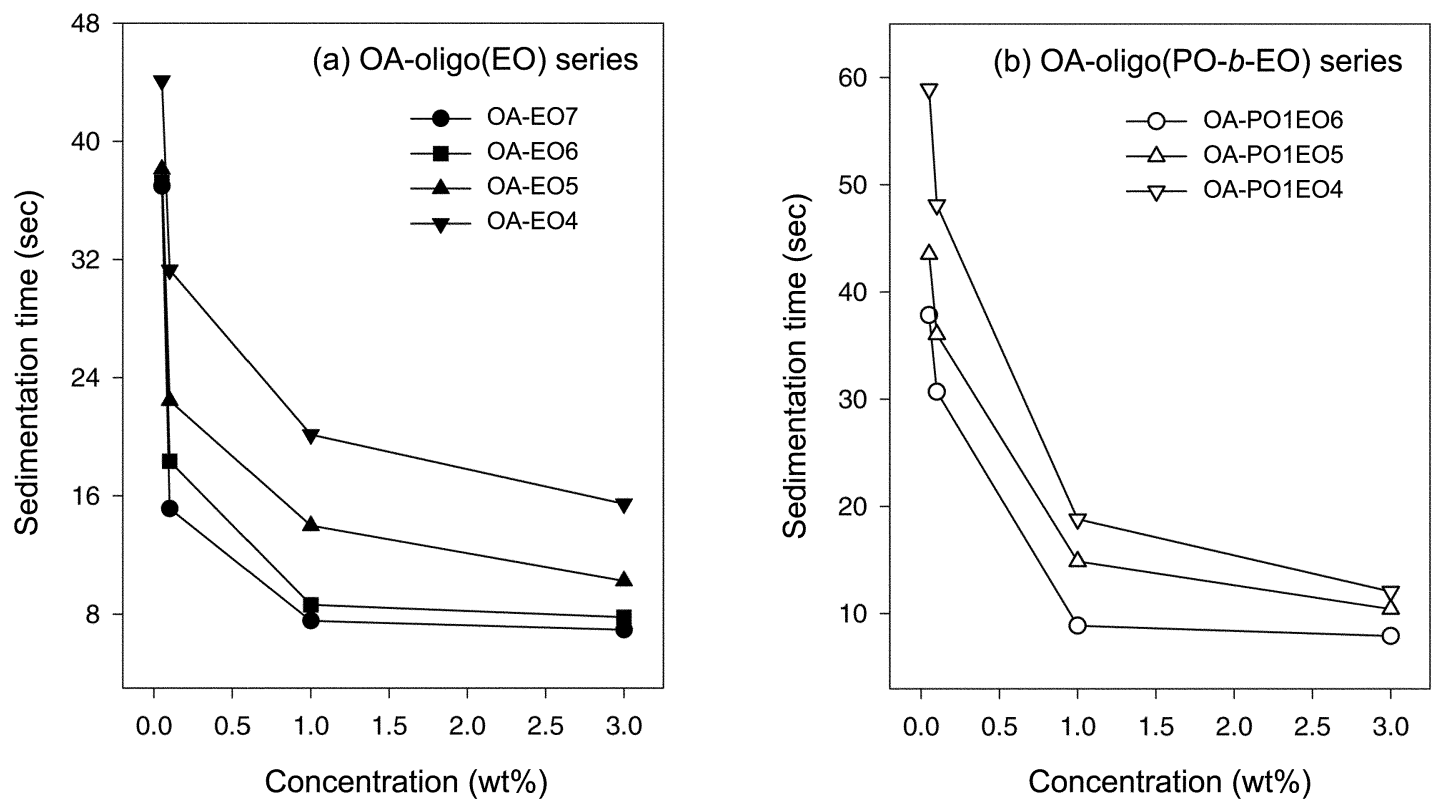

Figure 6. The sedimentation time of the $\mathrm{OA}$-oligo(EO) and $\mathrm{OA}$-oligo(PO- $b$-EO) series.

time of the OA-oligo( $\mathrm{PO}-b-\mathrm{CO})$ series according to the variation of the $\mathrm{PO}$ ratio. As shown in Figure 6-(b), the sedimentation time of the OA-oligo(PO-b-EO) series tends to increase with increasing $\mathrm{PO}$ ratio. These results are opposite to the surface tension of the OA-oligo(PO- $b-\mathrm{CO})$ series. When siloxane surfactants were dissolved, hydrophobic surfactant molecules were regularly and densely arranged toward the interface of the aqueous solutions, but hydrophilic surfactant molecules were regularly arranged into the aqueous solutions. Therefore, as the substrate contacted on the surface of the aqueous solutions, the penetration of the hydrophobic surfactant molecules into the substrate occurred, and then the substrate rapidly precipitated into the aqueous solutions by the diffusion of hydrophilic molecules. These facts were seen in the surface tension. The surface of the aqueous solutions showed low surface tension due to the

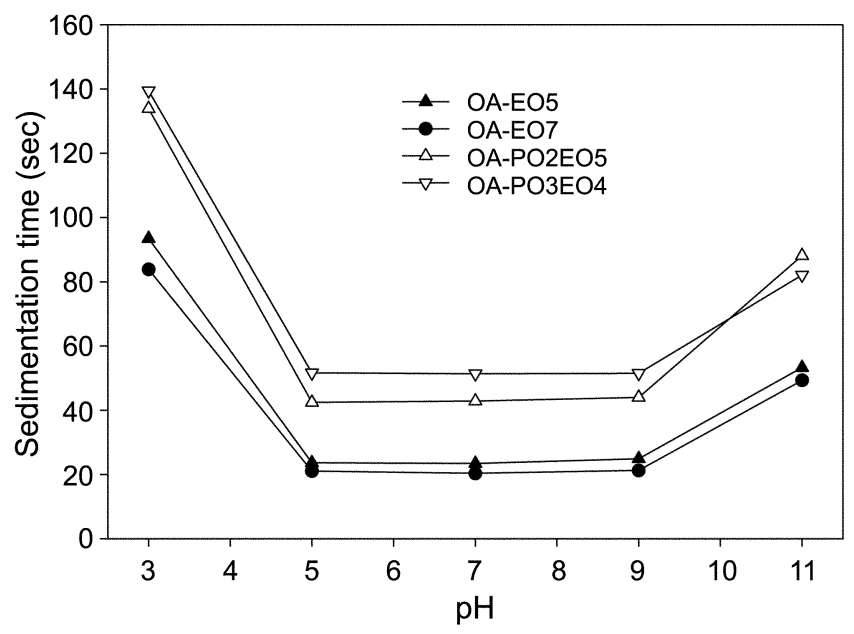

Figure 7. The sedimentation time of the OA-oligor $1: 0)$ series and $O \wedge$-oligo $(\mathrm{PO}-b-\mathrm{EO})$ series according to the variation in pll values. (Concentration of aqueous solution: $0.1 \mathrm{wt} \%$ ). surface arrangement of the hydrophobic molecules, such as the OMTS and PO unit. Otherwise, the inner part of the aqueous solutions showed high surface tension due to the existence of $\mathrm{\Gamma} \mathrm{O}$ moieties. Consequently, the wetting power of the aqueous solutions was increased because the sedimentation time decreased in the aqueous solutions as a result of the diffusion of molecules with the increase in the $\mathrm{EO}$ chain length. However, the sedimentation time increased in the aqueous solutions due to the dilution of hydrophilic molecules according to the increase of the PO ratio. Therefore, the wetting power increased.

Figure 7 shows the wetting power of the OA-oligo(PO- $b$ Г:O) series as a function of the sedimentation time according to the variation of $\mathrm{pH}$ values. As shown in Figure 7 , the sedimentation time of the OA-oligo(PO-b-ГO) series shows $U$-type curves according to the increase in $\mathrm{pH}$ values. In the case of $\mathrm{pH} 3$ and $\mathrm{pH} \mathrm{ll}$ as strong acid and alkali, the sedimentation time of the cotton piece in aqueous solutions was slow, but that of another cotton piece was fast in neutral $\mathrm{pH}$ values, such as $\mathrm{pH} 5$ and $\mathrm{pH} 7$. It seems that the variation of this sedimentation time resulted from the hydrolysis of the siloxane backbone as observed from surface tension data. ${ }^{2}$

Figure 8 shows the sedimentation time of the OAoligo $\left(\mathrm{l}^{2} \mathrm{O}-b\right.$-EO) series according to the content of inorganic electrolyte, respectively. As shown in Figure 8 , the curve shape of the sedimentation time was similar to that of surface tension. Generally, the sedimentation time of the OA-oligo( $\mathrm{PO}-b$-EO) series tended to increase quickly according to the increase in the electrolyte content. It seems that the decrease in the sedimentation time according to the content of inorganic electrolyte was similar to the reduction effects of surface tension. Therefore, hydrophilic EO groups were regularly arranged toward the interface because the addition of inorganic electrolyte accelerated the movement of the surfactant molecules toward the interface of aqueous 

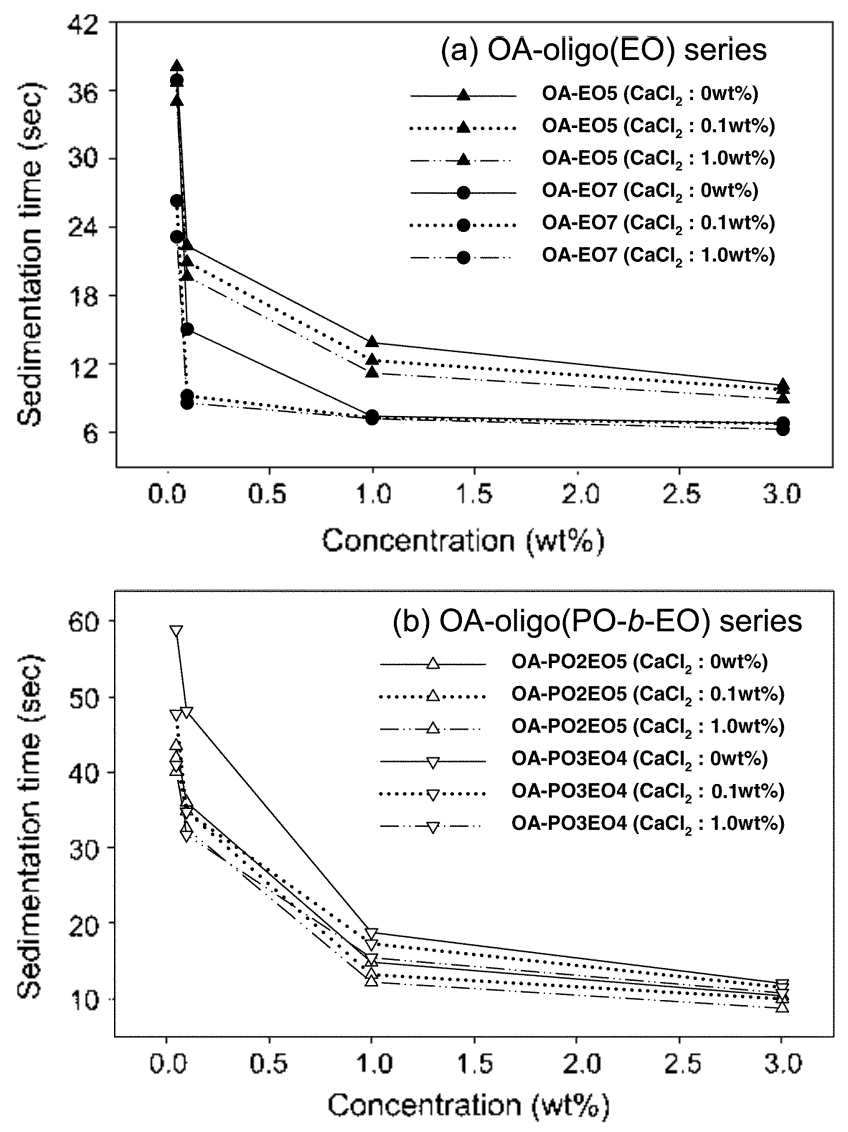

Figure 8. The sedimentation time of the $\mathrm{OA}-\mathrm{O}$ ligo( $\mathrm{LO}$ ) series and OA-oligo(PO- $h$-EO) serics according to the content of an inorganic electrolyte.

solutions. Consequently, the number of molecules at the interface of the solutions increased, and the wetting power increased, too.

\section{Conclusions}

In this study, polydisperse oligo( $\left({ }^{2} \mathrm{O}-b\right.$-EO) allyl ether siloxane surfactants were synthesized by the hydrosilylation reaction, and then their surface active properties were examined. Following conclusions can be drawn from this study.

1. The surface tension tended to decrease with decreasing EO chain length and increasing $\mathrm{PO}$ ratio.
2. The phase transition temperature increased with increasing CO chain length.

3. The sedimentation time and surface tension have high values at the $\mathrm{pH} 3$ or 11 due to the hydrolysis of the siloxane backbone.

\section{References}

1. Martin. I. In Suffactant Science Series: Randal. M., F.d.: Marcel Dekker Inc: New York, 1909: Vol 86, p 2.

2. Martim. I. In Surfactant Science Series: Randal. M. Ed.: Marad Dekker Inc: New York. 1999: Vol 86. p 97.

3. Kwicon. C.: Kim. D.: Cho. H.: Voh. S. I. Ind Ing (Whem 2003. 9. 146.

4. Wagner. R.: Wu. Y.: Grichochi. G.: Berlepseh. H. V.: Weiland. B.: Rexin. I.: Perepelittchenko. I. Appl. Orgartomatal. Chem. 1999. I3.611.

5. Wagner. R.: Wu. Y.: GLichocki. G.: Berlepsch. H. V.: Weiland. B.: Rexin. F.: P'crepclittchetiko. L. Appt. Orgamomatal. ('h'm. 1999. 13. 201 ,

6. Wagner. R.: Wu. Y.: Barlepsch. H. V.: 7astrow. H.: Weiland. B.: Perepelitlchenko, I. Appl. Organometal. Chem. 1999. 13.845.

7. Wagner. R.: Richter. L.: Weibmuller. J.: Reiners. J.: Klein. K. D.: Schaeler. D.: Stadimuller. S. fppl. Organometal. Chem. 1997. II. 617.

8. Wagner. R.: Richter. I.: Wu. Y.: Wuibmuller, J.: Ruiners. J.:

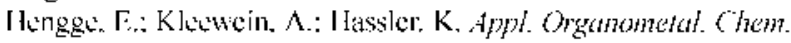
1997. 11.645

9. Goddard. E. D.: Ananthapadmanabhan. K. I? Intersetion of Sinfactants with Polymers and Proteins: C.RC Press: New York. 1992 .

10. Chattopadhyay, A. K.: Ghaicha, I.: Oh, S.: Shah, D, f. of Plncices Chenistry 1992, 96.6509 .

1 1. Cientle. T. I:.: Snow. S. A. Lomgnuir 1995. //. 2905.

12. Lestel. L.: Cheradame. H.: Boileau. S. Pohmer 1990. $3 /$. 1154.

13. Cancouct. P.: Pernin. S.: Helary. G.: Sauvet. G. I. Fofyn. Ser. Purt . 2000.38 .837$.

14. Paquatte. I. A. Encyclopedia of Reagents for Organic Swhthesis 1991). 4. 2721 .

15. Chalk. A. J.: Harrod. J. F. JiCS 1965. 87. 16.

16. Cancouet. I’: Daudet. E.: Helary. G.: Moreau. M.: Sauvel. G. $J$. Polm. Sei. Put A 2000. 38.826.

17. I.im, C.: Kim. D.: Noh, S. J. lind. Eng Chem. 2003. 9.526.

18. Kim. D,: Noh. S. J. Ind Eng. (hem. 2003.9.537.

19. Kin. 13.: Noh. S. J. Appl. Polym. Sci. 2004. 92. 3292.

20. Hill. R. M. (wt Opin. Coll. Interface Sci 1998. 3.247.

21. Oh. S.: Moon. S.: Lee. D.: Kang. Y. Bull. Komean Chem. Soc. 2004. 25.280

22. Wang. Il: Ciao, H.: 7.hao. I. Bull. Korean Chem. Soc. 2003. 24. 1444. 